\title{
Para uma análise linguística do conto "Sobre da morte de Bieito" de Rafael Dieste: referenciação, enunciação e modalidade
}

\author{
Benjamim Moreira \\ Universidade de Santiago de Compostela
}

\section{Introdução}

Perante um texto literário somos levados, enquanto leitores, a imaginar que basta olhar para esse objecto que aí está, diante de nós, que é suficiente lê-lo para que de imediato o objecto se recorte sozinho. Poderemos até confiar no crítico literário que Sainte Beuve define como aquele que sabe ler e que ensina os outros [isto é, aqueles que não são capazes de ler o texto literário] a ler.

Porém, uma análise literária, como qualquer prática, enquanto não atinge um nível de conceptualização coerente, pode facilmente incorrer na ilusão empírica de exterioridade do objecto; nesse caso, a experiência do contacto com o texto ilude o distanciamento necessário que o texto enquanto objecto de conhecimento exige.

A linguística pode, a minha opinião, ajudar um crítico literário a proteger-se dessa ilusão empírica: a da exterioridade do objecto de análise.

Não pretendo com isto afirmar que a análise linguística (de entre outras disciplinas) esgote a análise literária. A linguística não pode substituir-se à análise literária, mas pode obrigá-la a colocar-se problemas metodológicos e teóricos fundamentais.

Sabemos, por outro lado, que o texto literário tem sido utilizado pela linguística como ilustração ou confirmação de teorias, ou melhor, pequenos excertos textuais têm servido de forma mais ou menos arbitrária para a descrição linguística. No entanto, e sobretudo a partir dos trabalhos de Benveniste e dos contributos teóricos de Culioli, nos últimos anos as teorias enunciativas têm reivindicado para a 
linguística o estudo da especificidade do enunciado, do texto ficcional', mesmo sabendo-se que

un texte dit aussi en ne disant pas quelque chose, et qu'il faut en outre démasquer (parce que le langage est aussi masque) ce qu'il donne l'impréssion de dire, alors qu'en fait il ne le dit pas (Culioli 1971: 71).

Partindo do texto e observando a materialidade verbal, o linguista procura captar os diferentes valores que os marcadores manifestam, sobretudo aqueles que lhe permitem teorizar construindo uma problemática. Nessa perspectiva ele interessar-se-á preferencialmente pela variação, pelas modulações do que é dito mais do que aquilo que é propriamente dito, captando a especificidade de uma determinada forma e em consequência revelando "novas dimensões de interpretação" (Campos no prelo).

\section{Construção do objecto}

Não é meu objectivo explicar o conto Sobre da morte de Bieito ${ }^{2}$ de Rafael Dieste mas, centrando-me em alguns aspectos linguísticos, procurar mostrar um modo de utilizá-los com interesse na argumentação literária. O campo de análise é forçosamente limitado e de modo algum visa reflectir toda a riqueza do texto diestiano. As observações mais ou menos avulsas incidindo sobre o funcionamento de algumas categorias gramaticais também não serão exaustivas, pretendem apenas levantar algumas questões de materialidade textual susceptíveis de constituir alguma relevância na percepção do texto enquanto agenciamento de marcadores de operações não directamente perceptíveis na superfície do texto (cfr. Culioli 1990).

As observações que efectuaremos prendem-se a alguns aspectos que podem constituir campos de estudo mais ou menos interessantes relativas a três planos de análise: o da referenciação, da enunciação e da modalidade.

\section{Os três planos de análise}

Por um lado a organização temporal da narrativa é construída partindo do localizador temporal quando (logo na primeira linha mas também ao longo do

\footnotetext{
Vejam-se, por exemplo, os trabalhos de Benveniste (1966) e os contributos teóricos de Culioli (1971,1990) e Danon-Boileau (1995), Fonseca (1994), Carreira (no prelo), Campos (no prelo).

2 Para este trabalho utilizamos a versão incluída em Dos Arquivos do Trasno, $7^{a}$ ed., Colección Literaria, Editorial Galaxia, 1999, pp. 9-14. As diferenças encontradas nas diversas edições que pude consultar, nomeadamente as de 1962 e 1973 além da de 1999, exigiriam um outro tipo de estudo que não cabe aqui realizar. O próprio título mereceria por si só uma investigação que descrevesse, explicando, o percurso de Sobre a morte de Bieito (1962) a Sobre da morte de Bieito (1999) passando por Encol da morte de Bieito (1973) entre outras edições.
} 
conto) reforçando desse modo o efeito proléptico pois, como assinala DanonBoileau (1995: 19), as proposições que estão a seguir a um localizador temporal determinam um momento essencial na narração. No conto de Dieste, "cando eu sentín boligar dentro da caixa ó pobre Bieito" é assim o momento fundador da narrativa. O conto será então o corolário das consequências das sensações auditivas ou mentais do narrador.

Mas, nessa dimensão temporal, o plano enunciativo central é o tempo da enunciação $\left(\mathrm{T}_{2}\right)^{3}$. Este localizador é posterior em relação ao plano narrativo em que se inserem os acontecimentos relatados $\left(\mathrm{T}_{3}\right)$ e apresentados logo na abertura pelos localizadores espaciais, temporais e pelo valor perfectivo do pretérito perfeito simples e que correspondem aos factos relativos ao funeral (plano referencial). É também nessa situação enunciativa $\left(\mathrm{Sit}_{2}\right)$ que o Enunciador constrói um tempo $\left(\mathrm{T}_{4}\right)$ fictivo em que estão localizadas as alternativas ao estado de coisas descritas (plano modal). É também aí - $\mathrm{Sit}_{2}\left(\mathrm{~T}_{2}\right)$ - que se situa o diálogo do narrador com o narratário e em que se manifesta a tentativa de explicação/justificação das atitudes do próprio enunciador. $\mathrm{T}_{4}$ é apresentado como posterior a $\mathrm{T}_{2}$ e a $\mathrm{T}_{3}$ mas trata-se na realidade apenas de um efeito de sentido provocado pela avaliação que o enunciador faz dos acontecimentos e na sua estratégia argumentativa/justificativa. $\mathrm{T}_{4}$ é assim temporalmente anterior a $\mathrm{T}_{2}$ mas, ao afastar-se da verdade dos conteúdos proposicionais dos enunciados assertivos relativos a $\mathrm{Sit}_{3}$, o enunciador modaliza-os em $\mathrm{T}_{2}$, ou melhor, remodaliza-os. Temos assim uma oposição entre o nível temporal e o nível modal. Estamos perante uma reconstrução fictiva: ao sobrepor o plano modalizado ao plano assertivo, o enunciador cria expectativas que constituem, no plano literário, o fermento da leitura, para usar uma metáfora abusiva. Para esse efeito contribuem os mecanismos linguísticos, suportes epistémicos das dúvidas do narrador, que se projectam sabiamente no narratário quando afinal não passam de construções fictícias já que não alteram em nada o estado de coisas, a descrição do mundo que lhe está subjacente e que pertence ao universo do perfectivo.

Também a conjunção pero no início do segundo parágrafo é o marcador de um regresso do enunciador ao discurso pondo argumentativamente em evidência a existência de dois pólos/dois caminhos/duas forças opostas: dizer/não dizer que Bieito estava vivo. Como uma força -a do dizer- não é sentida como, pelo menos eticamente, a mais forte, o enunciador precisa de reforçar a força argumentativa com apelos directos à compreeensão do interlocutor (verbos no imperativo: comprendede, escoitade). A modalização conclui esse esforço de persuasão do narratário, como acto de justificação de uma escolha/decisão, eticamente pelo

Reservamos $\operatorname{Sit}_{0}\left(\mathrm{~T}_{0}\right)$ para a Situação (Tempo) de Enunciação origem e $\operatorname{Sit}_{1}\left(\mathrm{~T}_{1}\right)$ para a Situação de locução. 
menos, inaceitável. Notemos que em primeiro lugar esta modalização pode e deve ser entendida como uma tentativa de auto-justificação da decisão que se tem dificuldade em aceitar, tentativa que não parece completamente coroada de êxito porque novas marcas dessa pouca certeza da correç̧ão da atitude vão surgir posteriormente no texto (mesmo com as tentativas de antevisão de atitudes e de comportamentos de terceiros se o narrador tivesse decidido falar ${ }^{4}$ ). $\mathrm{O}$ enunciado interrogativo disjuntivo Sentino ou foi aprensión miña? coloca do lado do coenunciador a responsabilidade da validação de uma ou de outra relação predicativa dado que o enunciador não quer ou não pode assumir o seu valor de verdade.

\section{Breve análise de duas manifestações da modalidade}

Apesar de a modalidade constituir uma categoria que está presente em todo e qualquer enunciado (Bally 1944: 35) e o modo, a expressão da atitude de quem fala relativamente àquilo que diz (Lopes 1971: 245), vamos considerar apenas duas manifestações explícitas de modalidade: no início do conto (non podía, non debía dicir nada, no segundo parágrafo) e no final (Ía dicir, no penúltimo parágrafo).

No entanto, ao longo do texto vão-se acumulando marcas modais de dúvida do enunciador face à verdade das proposições, gerando (ou justificando) o sentimento geral de insegurança (a) sentino ou foi aprensión miña; (b) non tiña seguranza; (c) a exclamação ¡Foi um rebulir tan maino...!; (d) Ah! ¿E se entonces, ó ser

\footnotetext{
Lembro aqui que o problema base deste conto é: falar/não falar, dizer/não dizer: Nos tribunais a fórmula exemplar será: quem tiver alguma coisa a dizer que o diga, se não cale-se para sempre. Ora, este conto é exactamente o desenvolvimento do que é falar depois do assunto encerrado. Ou seja, o dizer já não vai alterar o estado de coisas, a ordem do mundo, e por isso o narrador não devia falar exactamente porque calou no momento em que teria de falar. O não assumir o acto de não falar (e não o pode assumir porque continua arrependido ou pelo menos perturbado) conduz o narrador a procurar justificar os seus actos como se houvesse uma justificação. Esse estado de espírito muito pouco sossegado leva-o, inclusivamente, a dirigir-se ao narratário, quase implorando a sua compreensão, ou, diríamos melhor, o seu perdão. Como ele próprio não se consegue perdoar a si mesmo procura no exterior a compreensão e logo o perdão. A linguagem tem também essa função. O que é interessante é que o texto parece representar uma cena no psicanalista ou no confessionário. A necessidade de argumentação leva o locutor a colocar-se como ser individual, desprotegido, indefeso por oposição a todos (veja-se a reiteração do quantificador). É que é precisamente o facto de ser único que o leva a essa insegurança, ou seja, o Eu vs. os Outros. Também é o facto de ser o único a ouvir a voz do defunto que lhe gera hesitação mas não parece ser esse o problema fundamental.

Uma análise mais desenvolvida teria de explicar a relação eu/outros (veja-se o número de ocorrências de 'todos') e a construção de um mundo alternativo através do convite ao narratário 'imaginade' e o uso do condicional.
} 
aberto o cadaleito, a miña sospeita resultaba falsa? (e) mais entonces acudiu novamente ó meu maxin a case seguranza do arrepiante ridículo, da rabia da familia defraudada, se o Bieito se topaba morto e ben morto. (f) No seo da terra unhas unllas desesperadas rabuñaban nas táboas. Rabuñaban? Non sei, non sei; as conclusivas (a) polo tanto non podía, non debía dicir nada; (b) Por iso non dixen nada; as interrogações retóricas como xustificar o non ter dito? Ía dicir que o deixara enterrar sabendo que estaba vivo?; a construção de hipóteses que representem o mundo alternativo resultante de o enunciador ter falado (o estado de coisas não verificado) introduzidas pelo quantificador todo, todas, todos, o ser colectivo -os outros, por oposição ao ser individual - o eu; a preocupação em captar a simpatia e a sintonia do leitor para melhor o persuadir dos seus argumentos (não ter falado): (a) meus amigos; (b) comprendede, escoitade; (c) Imaxinade; (d) Comprendedes?

4.1 No segundo parágrafo: Pero é que eu, meus amigos, non tiña seguranza, e polo tanto - conprendede, escoitade - polo tanto non podía, non debía dicir nada.

As marcas de modalidade non podía, non debía fazem sentido num contexto de resposta a uma objecção pelo menos implícita por parte do coenunciador. Nesse sentido de justificação interagem também o marcador conclusivo "polo tanto", o vocativo, o tempo e a forma imperativa dos verbos "comprendede, escoitade". Uma operação de sobremodalização procura desfazer qualquer réstea de objecção que o enunciador atribui aos "meus amigos" (leitores). Assim, a precaução é maior quando a uma modalização com poder (non podía) -também ela susceptível de uma objecção dado que "poder sempre se pode"- se acrescenta uma modalidade deôntica marcada com dever (non debía). Esta última forma é a marca do conflito entre aquilo que o sujeito pensa e aquilo que o sujeito pensa que o outro pensa. A uma sobremodalização do poder segue-se uma remodalização com o dever. Digamos que estão em causa duas atitudes opostas face a um mesmo facto: dever ou não dever falar/ dever ou não dever dizer. Estamos portanto num conflito de representações inscritas numa relação intersubjectiva.

Uma característica do modal dever, comum à diversidade dos valores que este verbo pode assumir, é o seu comportamento quando em coocorrência com a negação marcada pela partícula não: não dever $p$ é, do ponto de vista estritamente semântico, equivalente a dever não-p. A partícula não incide semanticamente sobre a relação predicativa $\langle\mathrm{p}\rangle$ : $<$ eu, dizer nada $>$, e não sobre debía (Campos 1998: 119). Quando a modalização marcada por dever é negada, não é o valor modal que é semanticamente negado mas sim a relação predicativa. Dá-se o fenómeno sintáctico habitualmente designado por 'subida da negação' (Campos 1998: 125). 
Uma representação bifurcada dos caminhos que os modais poder $e$ dever constroem pode ajudar a ver as diferenças fundamentais que o valor deôntico tem nesses dois casos pondo em destaque a força modal associada a não poder ${ }^{5}$ :

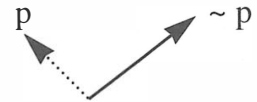

não pode $\mathbf{p}$

"tem de $\sim \mathrm{p}$ "

(a)

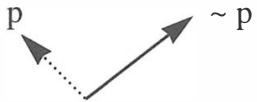

não deve $\mathbf{p}$

"deve $\sim$ p"

(b)

(a) o valor de não pode $\mathbf{p}$ está representado pela construção do caminho para $\sim \mathbf{p}$, ao mesmo tempo que se bloqueia o caminho para p; equivalente a "tem de não-p";

(b) o valor de não deve p: é construído o caminho para $\mathbf{p}$, mas não é bloqueado o caminho para p; equivale a "deve não-p";

(c) $\mathrm{O}$ valor de não pode $\mathbf{p}$ é mais forte que o de não deve p; não poder $\mathbf{p}$ é uma forma argumentativamente mais forte do que não dever $\mathbf{p}$;

(d) Estamos portanto perante uma interpretação mais forte em non podía, equivalente a uma asserção estrita, que em non debía. Trata-se de uma remodalização -enfraquecimento do valor assertivo- e não de uma negação metalinguística.

(e) Esta representação gráfica permite também compreender a escolha do locutor: com non debía recupera-se a bifurcação, ainda que um dos ramos seja distinguido. A asserção non podía dicir nada é localizada em relação à relação predicativa eu non tiña seguranza, localizador na relação interproposicional construída.

4.2 Antes de analisarmos o segundo caso, vejamos de passagem na linha $47 \mathrm{o}$ enunciado:

mais o crego acabou e a caixa deceu á cova sen que eu puidese dicir nada. $\mathrm{O}$ valor assertivo de sen que eu puidese dicir nada é claro, mas também o é o valor perfectivo. Se dividirmos o conto em duas partes, sendo a primeira correspondente

"Diagrama adaptado de Campos (1998: 127) e do exemplário distribuído na conferência "Sobre a modalidade em português" que Campos proferiu na Faculdade de Filologia da Universidade de Santiago de Compostela no dia 8 de Maio de 2000 (não publicado). 
a uma explicação/justificação do 'não dizer' e a segunda à justificação do 'não ter dito', estamos, agora com o conjuntivo, a passar para a segunda, hipótese confirmada pelo narrador logo de seguida como xustificar non o ter dito antes? ${ }^{6}$. Do indicativo -imperfeito- transita-se agora para o conjuntivo que marca valores que não lhe são normalmente atribuídos: a construção da relação predicativa é anterior à situação de enunciação (pré-construção).

4.3 Observando o enunciado Ía dicir que o deixara enterrar sabendo que estaba vivo? verificamos o entroncamento dos três planos de que falámos atrás. O plano referencial perfectivo relativo a três dados associados: primeiro, não disse (que sabia que Bieito estava vivo), segundo, deixou-o enterrar (vivo); terceiro, Bieito estava vivo (quando foi enterrado). O plano enunciativo é construído a partir da Situação de Enunciação presente e projecta-se temporal-aspectualmente no passado. A construção Ía dicir que é localizada em relação à relação predicativa sabendo que estaba vivo, localizador na relação interproposicional construída, donde surge o valor modal da interrogação retórica. Ía dicir que corresponde então ao valor forte de non podia dicir analisado em 4.1.

O conto termina assim como começou: a impossibilidade de dizer/de falar. No entanto, é caso para associarmos o dito comum "quando uma mão aponta para a lua o parvo olha para o dedo". Afinal, só no final do conto os cães uivam, para a lua ou para o pobre Bieito que acaba, então, de morrer.

\section{Engastamento dos três planos}

Interessando-nos fundamentalmente verificar a inter-relação dos três planos deixamos de lado o estudo dos sub-níveis que eles comportam e que poderão também eles confluir noutros relacionamentos.

\subsection{Articulação dos três níveis}

Os três níveis maiores detectados dizem respeito ao plano histórico (I), ao plano enunciativo (II) e ao plano modal (III). Outras designações podem ser utilizadas respectivamente: plano referencial (I), do discurso (II) e avaliativo (III). Têm de comum estes três níveis o facto de o Enunciador os construir sempre a partir do momento da Enunciação (T2).

O nível I é construídọ através de uma translação marcada no texto pela presença do pretérito imperfeito do indicativo projectando-se no pretérito perfeito simples

\footnotetext{
- Note-se que já anteriormente o locutor afirmara, no pretérito perfeito, Por isso non dixen nada.
} 
desde logo iniciado com a primeira forma introdutória "Foi" seguido da localização espacial da narrativa que se pretende objectiva. O localizador enunciativo é o presente da enunciação. Neste plano se situa o funeral de Bieito. Localizador temporal: estado para que remete o pretérito imperfeito (dos catro levadores do cadaleito eu era un; entonces; tódalas testas dos velliños que portaban cirios) $)^{7}$.

O nível II não tem marcas directas apesar de constituir o termo ${ }^{8}$ localizador de todas as operações de referenciação. Ele pode ser reconstruído a partir da alteridade de que o pretérito perfeito simples é marcador (do mesmo modo que através do mecanismo de alteridade também o nível II é construído a partir do mundo fictivo representado no nível III. O diálogo narrador-narratário é assim o ponto de fuga para trás mas também para a frente, para o nível I, e para o nível III. É no nível II que se situa o drama do narrador face ao narratário, constituíndo o que Casas (1995: 63) designa "a tensión do instante en que se dá a coñecer ese suceso aos oíntes-lectores". O marcador temporal "entonces" (Entonces non podería aseguralo) é construído a partir do tempo da enunciação e por oposição a ele.

O nível III é construído no nível II, isto é, no presente da enunciação, mas como posterior em relação a I exactamente porque alternativo ao estado de coisas representado no nível I. Trata-se portanto de uma hipótese não verificada -a interpretação de que Bieito fora enterrado vivo é uma certeza-: non podía, non debía dicir nada; Comprendedes? Por iso non dixen nada; sen que eu puidese dicir nada.

\subsection{Os dois subsistemas modais e sua articulação com os três níveis}

São duas as perspectivas construídas na Situação de Enunciação e que podem ser representadas num diagrama triangular. $\mathrm{O}$ ponto em que se situa o enunciador e o caminho para duas pontas sendo cada uma delas ocupada pelos dois subsistemas modais: o dever e o poder (neste caso também Ía dicir que anteriormente analisado). Digamos que a um corresponde a remodalização e a outro a sobremodalização de que as passagens seguintes dão conta:

(a) Sentino (nível I - passado - referencial) ou foi aprensión miña? (nível II presente);

(b) Entonces non podería aseguralo (então - nível I vs. agora - nível II)

7 Os dois planos, o referencial e o plano fictício encontram-se engastados. Na realidade, a perspectiva enunciativa tem como localizador origem T0, o Tempo da Enunciação origem.

8 Usamos 'termo' enquanto conceito abstracto capaz de suportar uma variedade de manifestações linguísticas ou metalinguísticas. 
(c) non tiña seguranza (tinha vs. tenho; passado vs. presente), e polo tanto non podía, non debía dicir nada

(d) Mais o crego acabou e a caixa deceu á cova sem que eu puidese dicir nada

(e) Ademais o dicilo tan tarde acrecía o absurdo desorbitadamente. Como xustificar non o ter dito antes?

(f) No seo da terra unhas unllas desesperadas rabuñaban nas táboas. (Nível referencial). Rabuñaban? (Modalidade epistémica interrogativa) Non sei, non sei. (epistémica; reiteração)

(g) cando fiquei suspenso

(h) Entonces si que sería absurda, tola, a miña presencia alí...

(i) Ía dicir que o deixara enterrar sabendo que estaba vivo?

Os dois níveis modais prendem-se portanto aos paradigmas da certeza, segurança vs. incerteza, dúvida, insegurança. Nesse sentido, todo o texto é um agenciamento de marcadores do conflito de representações opostas: falar/não falar, dizer/não dizer, falar/calar. A coerência do texto surge precisamente do acto da construção de um espaço de alteridade, intersubjectivo, em que o enunciador coloca o outro, atribuindo-lhe a modalidade do falar/dizer. O texto é assim, marcadamente explicativo/ justificativo da modalidade escolhida pelo enunciador: não falar/não dizer. Claro que a posição que o enunciador atribui ao outro pode mais não ser que o resultado de um monólogo interior capaz de pôr em cena o dialogismo imanente ao próprio enunciador. Essa necessidade de explicação/justificação aparece já no título que sendo catafórico é também anafórico porque não parece pretender refazer nada em relação à morte mas justificar uma atitude.

\subsection{0 título}

Refazendo a composição do título do conto Sobre da morte de Bieito teremos também os três planos que delineámos antes e que se encontram sobrepostos (cf. o valor primitivo deas preposições de/sobre):

(a) a morte de Bieito: ([d]a morte) a determinado, a existência da morte é um préconstruído na situação de enunciação.

(b) da morte de Bieito: na Situação de Enunciação o Enunciador tem dados para acrescentar à versão conhecida da morte de Bieito.

(c) sobre da morte de Bieito: ou da impossibilidade de em momentos diferenciados poder dizer da não morte de Bieito; ou da obrigatoriedade de não dizer nada acerca de (b). 
A conjunção destes planos, arrastando e enebriando o leitor perplexo até ao final, mais não é do que o remuíño que fan arredor dunha lámpada moitas bolboretas, todas mergulladas na mesma luz, como declara Dieste no Limiar Dos (seus) Arquivos de Trasno.

\section{Referências bibliográficas}

Bally, C. (1944): Linguistique générale, linguistique française (Berne: A. Francke S.A).

Benveniste, É. (1966): Problèmes de linguistique générale, 1 (Paris: Gallimard).

Campos, M. H. Costa (1998): Dever e Poder: um subsistema modal do português (Lisboa: Fundação Calouste Gulbenkian / JNICT).

Campos, M. H. Costa (no prelo): "Valores aspectuais no conto Jesus de Miguel Torga: uma análise linguística", Biblos, Volume de homenagem ao Professor Doutor José Gonçalo Herculano de Carvalho.

Carreira, M. H. Araújo (no prelo): "La création lexicale dans la fiction portugaise. De la morphologie lexicale à la combinatoire discursive", Actes du Colloque "La Néologie Ibérique » (Paris: Publications de la Sorbonne).

Casas, A. (1995): "Elementos para unha teoría literaria", en Casas, A (coord.), Tentativas sobre Dieste (Santiago de Compostela: Sotelo Blanco).

Culioli, A. (1971): "Un linguistique devant la critique littéraire", Cahiers de la Faculté des Letttres de Clermond-Ferrand (Paris: Ophrys).

Culioli, A. (1990): Pour une linguistique de l'énonciation (Paris: Ophrys).

Danon-Boileau, L. (1995): Du texte littéraire à l'acte de fiction : lectures linguistiques et réflexions psychanalytiques (Paris: Ophrys).

Dieste, R. (1999) [1962]: Dos Arquivos do Trasno (Vigo: Galaxia).

Fonseca, F. I. (1994): Gramática e Pragmática (Porto: Porto Editora).

Lopes, Ó. (1971): Gramática Simbólica do Português (Lisboa: Fundação Calouste Gulbenkian). 